ESRC Centre for Analysis of Risk and Regulation

\title{
From Risks to Second-order Dangers in Financial Markets: unintended consequences of risk management systems
}

Boris Holzer and Yuval Millo 


\title{
From Risks to Second-order Dangers in Financial Markets: unintended consequences of risk management systems
}

\author{
Boris Holzer and Yuval Millo
}

\section{Contents}

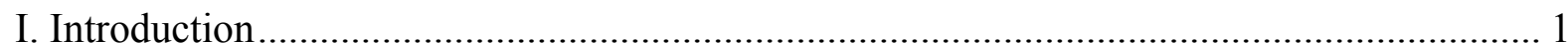

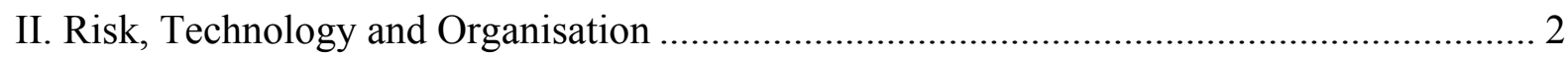

III. The Construction of Risks and Second-order Dangers in Financial Markets .................... 5

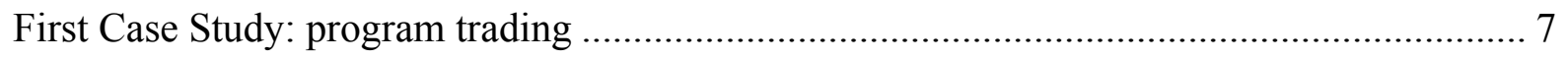

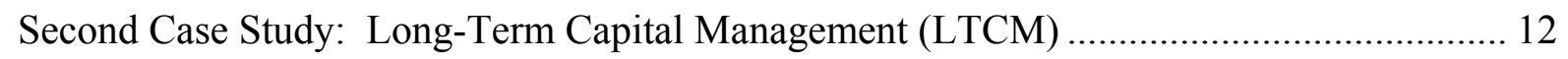

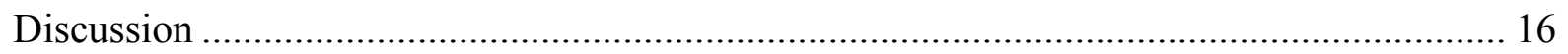

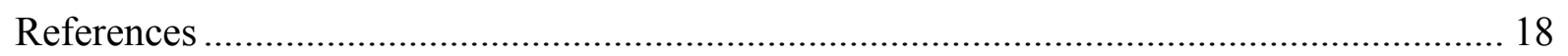


Dr. Boris Holzer

Department of Sociology, Ludwig-Maximilians-University Munich

Konradstr. 6

80801 Munich, Germany

Tel. +49 (0)89 2180-3220

Fax $+49(0) 892180-2922$

E-mail B.Holzer@Lmu.de

Dr. Yuval Millo (corresponding author)

Centre for Analysis of Risk and Regulation

London School of Economics and Political Science

Houghton Street, London WC2A 2AE

Tel 02079556346

Fax 02079556578

E-maily.millo@1se.ac.uk

As of January 2005:

Dr. Yuval Millo

Department of Accounting, Finance and Management, University of Essex

Wivenhoe Park, Colchester CO4 3SQ

Tel 01206874283

E-mailymillo@essex.ac.uk

The support of the Economic and Social Research Council (ESRC) is gratefully acknowledged. The work was part of the programme of the ESRC Centre for Analysis of Risk and Regulation.

Published by the Centre for Analysis of Risk and Regulation at the London School of Economics and Political Science

Houghton Street

London WC2A 2AE

(C) London School of Economics and Political Science, 2004

ISBN 0753017962

All rights reserved.

No part of this publication may be reproduced, stored in a retrieval system, or transmitted, in any form or by any means, without the prior permission in writing of the publisher, nor be otherwise circulated in any form of

binding or cover other than that in which it is published and without a similar condition including this condition being imposed on the subsequent purchaser.

Printed and bound by Printflow, November 2004 


\title{
From Risks to Second-order Dangers in Financial Markets: unintended consequences of risk management systems ${ }^{1}$
}

\author{
Boris Holzer and Yuval Millo
}

\section{Introduction}

The notion of risk is central to modern society, both as a productive and as a troublesome concept. On the one hand, risk refers to a situation of opportunity. Only those who undertake a risk, bear the uncertainties and face the potential adverse consequences, may gain the rewards. On the other hand, risk refers to fundamental uncertainty: at the time of risk-taking one cannot know for sure whether the opportunity concerned will be realised; in the worst case, the costs incurred might be greater than any benefit. Risk therefore increases the scope for both rational and seemingly irrational decisions: without the willingness to undertake a risk some opportunities may never be realised; the costs of an unsuccessful risky decision, however, may be intolerably high and may thus disqualify the whole enterprise in hindsight.

To some degree, the modern ambivalence about risk as something both positive and negative is reflected by a disciplinary division of labour. If economists talk about risks, they regard risk as the correlate of an uncertainty that makes entrepreneurial action possible. In contrast, when sociologists talk about risks they tend to think of the risks of technologies, the usage of which when unsuccessful, may bring about adverse consequences. To follow this disciplinary distinction means to accept that risk can occur on two analytically distinct levels: the one of the individual and the one of society. In this paper we argue that this dichotomy, between risk as an inherent element of entrepreneurship and between risk as an 'external' factor that should be minimised, is misleading. In fact, individual risk-taking and the societal management of risk are intertwined. We shall use two case studies from contemporary financial markets to demonstrate that an adequate understanding of the production of risk in modern society needs to take into account how sophisticated systems of risk management may result in unforeseen consequences and new dangers. The dichotomy between risk-taking and risk-management is undermined by the fact that the management of risk may become a new source of risk itself.

At first glance, risk in financial markets does not seem to lend itself to a sociological analysis. Sociological theory is not of much help in calculating the risk that a person undertakes when she/ he invests funds in market-traded assets. The question of how risk can effectively be

\footnotetext{
${ }^{1}$ Boris Holzer is a researcher at the department of sociology in Ludwig-Maximilians-University in Munich. He is a member of Ulrich Beck's research group and currently develops applications of the reflexive modernity thesis to contemporary financial environments. His latest publication (with Mads P. Sørensen) is: "Rethinking Subpolitics: Beyond the 'Iron Cage' of Modern Politics?" Theory, Culture \& Society, Volume 20, April 2003, 79102.

Yuval Millo is a researcher at the ESRC Centre for Analysis of Risk and Regulation at the London School of Economics. He studies organisational and social aspects of financial risk assessment systems. His latest publication (with Donald MacKenzie) is: "Negotiating a Market, Performing Theory: The Historical Sociology of a Financial Derivatives Exchange." American Journal of Sociology Volume 109, May 2003, 107-145.
} 
assessed and managed from an individual (or organisational) point of view is beyond the interest and explanatory scope of current sociological research. Nevertheless, the question of how risk-taking is shaped by financial markets is important to the sociological understanding of contemporary society. In particular, the study of this question becomes even more relevant in the light of an evolving trend in sociological literature that studies financial markets. Decisions in financial markets are not made in a social vacuum but rely on and utilise established networks and opportunities for mutual observation ${ }^{2}$. To the extent that market participants are influenced by their observations of others, the 'mutual susceptibility' of actors contributes to the emergence of 'social connectivities' within markets (MacKenzie, 2004).

In this vein, this paper seeks to contribute to the recent endeavour to go beyond the still dominant emphasis on atomistic decision-making in the analysis of financial markets. Mainstream financial economics asserts that there exist two separate realms that take part in decision-making in the markets: the agent who makes the decisions, and 'the market' - the environment within which the decisions are made and which ultimately 'computes' the consequences of those decisions. This conceptualisation tends to portray the individual decision-making agents as automata that follow a simple action-reaction pattern. We claim that this view cannot provide an appropriate explanation of decision-making in financial markets, because it does not take account of the multiple connectivities that underpin markets.

This does not only concern network ties of constant mutual observation among market participants, but also technological links. Decision-making in financial markets relies heavily on technology. Market participants make extensive use of mathematical risk management tools. Technological connectivities are created if many market participants use similar methods. We argue that under certain circumstances the combination of technical and social connectivities undermines the very possibility of operating effective financial risk management methods. We call this phenomenon 'second-order dangers'. Second-order dangers are the unintended by-products of systems of risk management and containment. Furthermore, we argue that the technological, social and organisational connections through which modern financial risk management is performed can produce, under certain circumstances, events that it cannot manage.

In the next two sections of this paper we establish the case for a sociological analysis of risk and second-order dangers in financial markets. In the second section we argue that technology and organisation play an important role in increasing the scope of and the reconfiguration of phenomena as risks. In the third section we focus the discussion on the reductive translation that is part of the construction of risks in organisational settings and show the relevance of these concepts to the development of modern financial markets. In the following two sections we analyse two instances in which the problem of second-order dangers in financial markets was manifested: the use of 'program trading' in the 1980s and the near-collapse of the hedge fund Long-Term Capital Management (LTCM). The paper is concluded by a discussion.

\section{Risk, Technology and Organisation}

The problem with traditional definitions of risk is that its antonym - safety - defies a positive definition. Safety is commonly defined through the relative lack of risk, but not as a quality in its own right. Safety may exist with regard to past events but not with regard to the future. The future is uncertain, and risk is a way to react to and actually make use of that uncertainty.

\footnotetext{
2 This basic theme of a sociological analysis of markets underpins much of the recent literature. See Smith (1981), Adler (1984), Baker (1984), Abolafia (1996), Knorr Cetina and Bruegger (2000), on financial markets and White $(1981,2002)$ and Leifer $(1987)$ on production markets.
} 
Yet, using the term risk indiscriminately, without a clear idea about which kinds of uncertainties deserve this special label and which do not, renders it useless. When do uncertainties result in risks? One analytical tradition calls for a conceptual definition that distinguishes risk from uncertainty. According to Knight (1921) uncertainty means that we have no information about possible future states of the world and their probabilities, while risk implies a partial knowledge of such probabilities. We do not dismiss the relevance of such a distinction between risk and uncertainty for a normative theory of action. For purposes of empirical research, however, Knight's terminology is not very useful. First, the envisaged objective information about probabilities is usually not available. How are we to distinguish between risk and uncertainty with regard to an economic forecast? Do figures alone justify speaking of 'probabilities' or do we need historical statistics (whose relevance for the future is unclear)? Second, the probability-based distinction does not seem to be clear-cut. Many situations entail some information about probabilities, while some aspects are completely uncertain.

Instead of an informational and probabilistic concept of risk, we employ a notion of risk that associates risk with decision-making (cf Luhmann, 1991). Risk characterises situations in which a loss (and a corresponding gain) is regarded as both possible and avoidable. Therefore, a decision needs to be made: to avoid the risk or to undertake it. Risk does not refer to 'objective' probabilities but to the 'subjective' expectation of possible damage related to one's decisions. Although knowing the probabilities can serve to legitimise risk-taking as such, it cannot eliminate the necessity of decision-making. The evaluation of a risky choice depends on the realisation of uncertain outcomes in the future and is thus only possible expost.

Therefore, the role of time is crucial for understanding risk. The probabilistic notion of risk abstracts from time by lumping together historical events into frequencies without a history. It adopts the perspective of the actuary: risk is 'calculable' to the extent that the occurrence of damages can be assigned a frequency-ratio. Relative frequencies can only be obtained if the undesired events occur frequently enough to form a sample on the basis of which statistical conclusions can be drawn. In contrast, history shows us that risk-taking situations are not 'seriable experiments', ie experiments that can be repeated under stable constraints again and again (cf Shackle, 1979: 134ff). Rather, risk invariably involves decisions that make a difference in the present and thus change the outlook for the future. Decisions are made at one point in time and their consequences are assessed at another ${ }^{3}$.

By focusing on decisions we put to the fore a factor that is often neglected in the conceptual analysis of risks - the attribution of choice and intentionality. It is then necessary to draw a distinction between risk and danger (Luhmann, 1990). While both risk and danger are related to the possibility of future adverse consequences, there is a crucial difference between the two. Risk is understood as the possibility of future damage that is attributed to a decision, ie to causes internal to a person or an organisation. Danger, in contrast, is the possibility of future damage that is attributed to the factors over which we have no influence. Thus, an earthquake would usually qualify as a danger, whereas a skiing accident would be regarded as a consequence of a risk that a person undertook. It is important to note that the distinction between risk and danger is the result of a social process of attribution. Whether a car accident is regarded as a danger or as a risk, depends on whether decision-making is believed to play a

\footnotetext{
${ }^{3}$ The time distance between decision-making and assessment is also highlighted by the notion of post-decisional surprise, ie the risk that we might regret a decision in the end, although it appeared to be the right decision at the time it was made Harrison, J. R. and. March, J. G (1984).
} 
role in it or not. For example, the likelihood of one's car being hit by a meteorite represents a danger, if a relatively small one. Yet, if a person decides to drive his/ her car during a hurricane warning, she/ he would undertake the risk that damage may occur. No one will attribute a meteorite accident to the 'risky' decision of the driver, but everyone will do so in the hurricane case. Put differently, nothing in itself is a risk or a danger. It becomes one through a social process of attributing undesired consequences to either someone's decision or external circumstances beyond decisional control.

Risk and danger are socially constructed categories of observation. A society that constructs certain phenomena in terms of risks looks different from one that constructs them in terms of danger. In particular, the more alternatives are available and the more social structures are subject to decision-making, the more risks are constructed. This approach can be useful in understanding the proliferation of risk in our society. Contemporary society is a 'risk society' (Beck, 1992) because it is a society replete with decisions, be it the decision to build a nuclear power plant, to make an investment, or to start a war. The making of such decisions reconstructs danger as risks: will the nuclear power plant be operative long enough to amortise its cost, will the investment be profitable, will the war be successful? In comparison to pre-modern society, modern society has greatly expanded the scope and impact of decisions.

How can we explain this phenomenon of 'risk explosion' in contemporary society? The historical processes through which risks became such a pervasive element of our time are beyond the scope of this paper. However, we identify two main factors that are especially pertinent to risk in financial markets: technology and organisations. The main vehicle for the expansion of risk has been technology. Technology can be conceived of as a way to transform dangers into risks. To use a very simple but convenient example: if one leaves the house, one always runs the danger of getting wet. It is a danger since rain is not, in our society, attributed to a decision ${ }^{4}$. A specific 'technology' - an umbrella - can transform rain from danger to risk. Once one has the option of taking along an umbrella, the question of whether or not to get wet depends on a decision: to use the umbrella or not. Technology plays a crucial part in transforming danger into risk (Luhmann, 1990).

Modern organisations are also an important factor in the construction of risk (Perrow, 1984; Short and Clarke, 1992). Much more than individuals, who are not normally required to reconstruct all their actions as the outcome of conscious decision-making ${ }^{5}$, modern, bureaucratic organisations are social systems of decision-making (Baecker, 1999; Luhmann, 2000). From the decision to hire someone as an employee to the decision to file for bankruptcy, modern organisations produce their own structures by decision-making. Most importantly, organising involves decisions that create premises for further decisions: decisions about personnel, hierarchies and rules. Flow charts, rules and procedures are but a few manifestations of this. One of the results of this modus operandi is that the environment in which the organisation operates is seen as constantly producing risks for the organisation. These risks are defined, assessed and managed through the various organisational paths. Organisations thus have a deep affinity to risk: they perceive themselves (and their environment) as the outcome of decisions, because whatever happens in an organisation can and must be interpreted as a decision. According to classical theory of bureaucracy,

\footnotetext{
${ }^{4}$ To be sure, the decision to go out in the first place may also be construed as acceptance of the risk of getting wet. Yet since it is impossible to stay at home forever, there is no real alternative, therefore any opportunity for decision-making: no risk, but danger.

${ }^{5}$ Even the most 'decisional' of sociological theories of action, rational choice theory, acknowledges that actors rely on routines and scripts rather than explicit decisions Esser, H. (1990).
} 
organisations are less concerned with instrumental rationality than with the creation and distribution of risk (Baecker, 1997).

Technology and bureaucratic organisation take part in an intertwined process through which a world of dangers is transformed into a world of risks. Organisational decisions are made based on alternatives and technology constantly provides new options - it offers new ways of action and thus makes it possible to conceive of more potential 'states of the world'. The world and its dangers are not 'givens' anymore, as technological tools make it increasingly a matter of decision to consider alternative futures.

\section{The Construction of Risks and Second-order Dangers in Financial Markets}

Since the 1970s we have seen the rise of both new technologies (derivative financial instruments in particular) and of organisations (in the form of institutional investors) in global financial markets (Lowry, 1984; Caytas, 1992; Hull, 1997; Steinherr, 1998). Over the last three decades, financial markets have gradually developed the tools and technology to transform many of the dangers embedded in economic activities into risks. With financial instruments related to more and more states of the world being traded on today's markets, even former natural dangers come within the scope of risk. For instance, the vicissitudes of the weather are not a danger but a risk for a farmer once she/ he can buy an appropriate weather-based financial instrument ${ }^{6}$. The more financial instruments are available, the more options there are to take a position or not. As a result, more future states of the world can be reconstructed as risks. We correspondingly conceive of financial markets as 'machines' that transform dangers into risks by bringing more and more uncertainties within the scope of decision-making.

In many respects, organised financial activity today is defined by the various practices through which the different dangers in the financial realm are defined, measured and thereby transformed into risks (Steinherr, 1998). The social and technological environments of financial markets have undergone a revolution that can be described as the risk turn. The connection between events in the outside world and their implications on the markets, a connection which existed implicitly in markets for centuries, has become more visible and tangible with the development of new methods for the quantitative representation of risk and with the evolution of financial contracts that turned those representations into tradable instruments.

New financial instruments such as derivatives constantly transform dangers into risks by reconfiguring them as part of decision-making processes. Financial derivatives became increasingly important during the 'privatisation of risk' (Bryan and Farrell, 1996) after the collapse of the Bretton Woods system. Previously, states had assumed the role of absorbing the consequences of a fixed exchange rate system. With fluctuating exchange rates, companies were exposed to new dangers that instruments such as currency swaps were designed to mitigate. In a world without futures, options and swaps, exchange rate fluctuations may constitute an external, uncontrollable danger to the operations of an export firm. With those tools, fluctuations are reconstructed as risk: firms can now buy appropriate FX (currency exchange) options or arrange currency swaps to guard themselves against the danger of adverse fluctuations in currency exchange rates.

\footnotetext{
${ }^{6}$ Trading risks related to natural disasters is nothing new and was traditionally the business of insurance and reinsurance companies. Yet the trading of weather-based standardised derivative contracts in organised exchanges, rather than as 'sold-once' over-the-counter products, is a recent development. Weather-based standardised derivative are currently traded in electronic exchanges in the US and the UK.
} 
The rapid development of the derivatives markets over the last few decades has been bound up with the emergence of modern financial economics. While the behaviour of financial markets had long seemed to be almost intractable, modern finance has provided the foundations for informed decision-making by making possible (and profitable) a 'reductive translation' of the uncertainties of the world. In the process of reductive translation, uncertainties are being described in terms of decisions that need to be made. One important step in this regard was the formulation of the option pricing model by Black, Scholes and Merton (Black and Scholes, 1973; Merton, 1973; see also MacKenzie, 2003). Before the development of the Black-Scholes formula, prices of options had been part of a larger uncertainty that encompassed the behaviour of capital markets. In contrast, the formula gave market participants an algorithm with which options prices could be calculated. The fundamental uncertainty of the fluctuation of share prices, their volatility, was thus transformed into a risk that could be distributed via the use of the formula. This was made possible because reductive translation performs two important tasks: it reduces the informational complexity of the data (namely, the number of informational items is reduced), and it represents the data in more constrained, but less ambiguous terms. As a result, the uncertainties of the future are increasingly subject to decision-making in the present - they are transformed into risks.

It has to be stressed that the development of settings in which dangers are recast as risks has not eliminated dangers altogether. In fact, as the analyses of two case studies in this paper show, by transforming dangers into risks, financial markets have created new uncertainties that could not be processed by the existing mechanisms of transformation, and could not be used as bases for decision-making. We use the concept of 'second-order dangers' to designate those consequences of the risk assessment systems of financial markets. Second-order dangers are the paradoxical side effects of the use of risk management systems in financial markets. Such use may bring about adverse events that the systems themselves cannot reconfigure as risks and therefore cannot manage. Such events are not attributable to decision-making and therefore cannot be regarded as risks, and since they are an outcome of a process in which initial dangers are reconfigured, they are of the second-order.

The transformation of dangers into risks does not result in a world without dangers. On the contrary, dangers in modern society are increasingly by-products of risk-management rather than unalterable 'external' forces. Such dangers are not 'primary' but 'manufactured' dangers - second-order dangers (Bonß 1995: 80ff). As the cases below show us, these dangers cannot serve as factors in the risk management process; they are unforeseen by-products of these processes. Thus, they take the form of 'new forces of nature' (ibid, 82), which cannot be adequately described - or mitigated - within the conceptual and calculative framework of risk management. Second-order dangers transcend the very framework within which risks are assessed and managed. Being the result of systems of risk management, second-order dangers blur the distinction between risk and danger: They are consequences of complex decisionmaking processes, but appear to be external forces beyond the control of any individual or organisation.

In the following section we present examples that explore the sources and forms of secondorder dangers in financial markets. Those dangers show that there exists an inherent problem in the contemporary dominant risk assessment methodology, a problem that leads to the emergence of second-order dangers. We discuss two examples: the use of computerised trading in the mid 1980s and the near-collapse of the hedge fund Long-Term Capital Management (LTCM). In the first case, we focus on the role of a particular risk strategy portfolio insurance. It represents an ingenious idea of how to construct market fluctuations 
(uncertainties) as risks that can be controlled. As a rather successful technology, it convinced many market participants to use this particular kind of risk management. Yet, since portfolio insurance, unlike other insurances, is not based on the 'law of large numbers', it could not work when everyone used it. Thus, a risk strategy resulted in a second-order danger that was ultimately created by a decision (to use portfolio insurance), but not anyone's decision in particular. In the second case, we discuss the case of LTCM, a hedge fund based on the idea of risk-free profit by arbitrage. Again a perfectly fine idea forced others to engage in similar activities, with the unintended by-product of changing the 'techno-social environment'. As a result, LTCM was not in a position to decide about its own portfolio anymore (ie to take a risk), but subject to the decisions of others (ie in danger).

\section{First Case Study: program trading}

One of the cases that can be used to illustrate the emergence of second-order dangers in financial markets is the growth of computer-based program trading in the early to mid 1980s. To understand how program trading contributed to the creation of second-order dangers, it is necessary to review the entrance of institutional investors to financial markets, the new trading strategies that these investors introduced, and the effect of these developments on the organisational and social structure of the markets.

The conceptual foundations behind financial derivatives contracts have existed for centuries (Bernstein, 1993). However, as mentioned earlier, the explosive growth of markets for financial derivatives began as late as the mid 1970s with the pioneering Chicago derivatives markets (Mackenzie and Millo, 2003). One of the trends that contributed greatly to the growth of financial markets in the last three decades was the increasing use that institutional bodies made of financial derivatives.

Traditionally, large institutional investors, like pension funds, refrained from entering the stock markets. The risks in those markets were regarded anathematic to worldview of institutions whose ultimate goal was the conservation of capital, rather than the making of profits. These institutions' attitudes to capital markets began to change in the early to mid 1980s, with the introduction of index-based derivatives contracts and the subsequent development of a new type of portfolio management techniques, known collectively as program trading. By buying index-based derivatives along with portfolios that were composed of stocks that made up the index (or were correlated with it), institutional investors were able to benefit potentially from higher rates of return than the ones that risk-free securities, such as government bonds, could provide, while still being protected from price drops. The organised trading of index-based contracts was first authorised in 1982. In April of that year, the Chicago Mercantile Exchange began trading a futures contract based on the Standard and Poor (S\&P) 500. By the end of 1982, the daily volume of that contract reached 20,000 contracts (Schwartz, Hill et al. 1986: 87-88). The popularity of index-based contracts continued to grow, and by the mid 1980s a significant proportion of institutional investors' financial assets were managed using index-based contracts ${ }^{7}$.

Institutional investors, who managed large inter-market portfolios, changed profoundly the economic environment in which small firms and individuals operated. Since the big institutional players of the early 1980s, such as Salomon Brothers, Sachs \& Company and Kidder, Peabody \& Company, operated simultaneously in several markets, the single-market traders could only see part of the picture. Hence, a broker executing sales when the prices

\footnotetext{
${ }^{7}$ For example, the SEC estimated that in 1986 between $\$ 30$ to $\$ 50$ billion of pension funds assets were invested in index-related contracts Securities and Exchange Commission, S. (1987): 1- 28
} 
were raising, for example, was not necessarily having any superior information to others, but could be simply carrying out one half of an arbitrage transaction. The information gap was accompanied by an economic one. Performing profitable inter-market arbitrage transactions was dependent on having large amounts of capital available. Discrepancies between the index and the futures contracts based on it were small, and to complete a profitable transaction (after the deduction of transaction costs) the arbitrageur had to buy and sell substantial amounts of stocks. In addition, the replication of large indices, like the S\&P 500, on which the most popular futures contract was based, was very costly, and was beyond the ability of all apart from a handful of large institutional investors.

The entrance of institutional investors to derivatives markets was accompanied by the introduction of new trading strategies. These strategies consisted of computer algorithms that performed high frequency, co-ordinated trading in both the stock markets and the derivatives markets. The establishment of immediate and influential connection between the prices in the stock markets and the derivatives markets is the fundamental factor behind the unfolding of second-order dangers in financial markets in the mid 1980s. To understand how these dangers came about we need to take a brief look at the two technical elements that enabled the creation of this phenomenon: index-based contracts and arbitrage trading.

Stock indices are calculated averages of the prices of set groups of stocks. For example, a list of 500 stocks complied by S\&P is used as a basis for the S\&P 500 index. On their own indices are merely mathematical abstractions that serve as indicators of the markets' situations. However, when incorporated into financial contracts, like futures or options, stock indices can serve as a useful market tool; since indices such as the S\&P represent the price movement of the market as a whole, they can serve as an underlying basis for financial derivative contracts. Some of the most popular derivatives contracts are known as futures. The futures contract obliges its owner (buyer) and its seller to pay or receive an amount of money proportional to the difference between the index level at the market on expiry and the index level stated in the contract. By using such contracts, market participants could defend their holding against sudden drops in prices. For example, a contract that would grant its owner, say, 25 dollars for each index point below a certain value at a certain date could serve as a safety net for investors. Similarly, a contract that would pay its owner 25 dollars for each index point above a certain value would make a good device for profit-seeking traders who hope to gain from increasing prices. Index-based contracts would also have a significant advantage over contracts written on individual assets. For example, the typical stock options contract is based on the market value of a single, specific stock. In contrast, index-based contracts, because they were based on a more general 'prices generator' - the index - were less specific. That meant that as long as a person's portfolio is correlated with the price movements of the whole market, a derivative contract based on a market-wide index could be used to supply protection against losses to that person's portfolio.

The entrance of big institutional investors to derivatives markets, and especially their use of index-based contracts brought about a change in the nature of the relations between these markets and the stock markets. Unlike small-scale market participants, who held relatively small portfolios of stocks, and used index-based derivatives as general protection, many institutional investors held and managed portfolios that replicated the complete catalogues of broad indices such as the S\&P 500. Institutional investors realised that they could use the dual representation of the index to make profits while limiting the risks involved. This was done through the application of a trading technique known as index arbitrage. Since the market price of index-based contracts derived from that of the stocks composing the index, 
theoretically, the former was to be in complete correlation with the latter ${ }^{8}$. In other words, neither the derivatives contract nor the average price of the stocks should be 'cheap' or 'expensive' in relation to the other. In practice, however, such price discrepancies occurred frequently. Market participants who held stock portfolios, that varied enough so that their market value followed the index closely, could use such discrepancies to perform 'index arbitrage'. In essence, arbitrage is based on selling the relatively 'over valued' asset in one market, while simultaneously buying the 'under valued' one at the other market. Most commonly, index arbitrage was performed through selling index futures, while buying the stocks that composed the index. The profits of this position would be realised at the expiry of the futures contract, or even before, when the arbitrager would 'unwind' the arbitrage position by buying back the futures contracts and selling the stocks.

The popularity of arbitrage-based strategies was one of the structural factors that contributed to the creation of second-order dangers in the financial markets of the 1980s. The performance of such trading strategies had a noticeable effect on the behaviour of prices in the stock markets. Through index arbitrage, the effects of external economic events were transmitted to the stock markets rapidly and, potentially, had an immediate impact on prices of stocks. The creation and unwinding of index arbitrage positions would mean that, as indexbased futures contracts would be traded, thousands of stocks, representing the composition of the index, would be bought and sold. This fact in itself may increase short-term volatility, although there exists no conclusive evidence that this was the case in the early 1980s (Securities and Exchange Commission, 1987; MacKenzie, 2004). However, a broader look at the effects of program trading shows that this trading strategy played a crucial part in the creation of second-order dangers in financial markets.

In the mid 1980s financial derivatives contracts that were traded in organised exchanges in large volumes were of three main varieties: options on individual stocks, futures based on indices and options on such futures. The majority of these contracts were written for periods of three months, typically expiring at the end of trading at the third Friday of the month in which the contract expires. Due to these standard time intervals, four times a year (on March, June, September and December) there occurred mutual expiration of stock options, index futures and index options. In such times, participants in stock markets witnessed huge sales orders that seemed to be completely unrelated to the known information about the stocks. Such waves of sale and buy orders, frequently amounting to millions of dollars, did not only leave the traders bewildered, but also caused significant losses to many veteran traders (Sterngold, 1986). These periods, immediately before the expiry of the contracts, came to be known as witching hours or witching days in the Wall Street parlance. The reason for this moniker was that market participants realised that during these near-expiration periods markets tended to display behaviour that was dramatically different from what was normally expected. It was gradually understood that usual patterns of trading did not hold true on those Fridays, and the markets behaved as if they were put under a mysterious spell.

Although witching hours caused confusion as to how markets would behave, market participants could detect easily their source. Witching hours were closely related to the ending stage of the index arbitrage transactions. The profit in such transactions was to be realised through buying back the futures contracts and selling the stocks that composed the index. The fact that the arbitrage positions were very large and that the sales typically took place close to the closing of the trading day (in an attempt to maximise the profits from the nearly-expiring

\footnotetext{
${ }^{8}$ The price of a futures contract, for example, is a function of the value of index, the time to the expiry of the contract, the carrying cost of the broker (in the case of financial derivatives, this would be equal to the risk-free interest rate), dividends to be paid for the stocks until the expiry.
} 
contracts) were responsible for the large and unexpected changes in stock prices. Frequently, the unwinding of arbitrage positions included selling many of the 500 stocks that made up the S\&P index. The share of arbitrage orders in relation to the overall trading in many of these stocks meant that computerised trading virtually determined the direction and the extent to which prices moved. The effect of a large 'sell' order, for example, on the prices of a particular stock would override the effects of most other news events or known parameters about the firm whose shares are traded.

As program trading in general, and index arbitrage in particular, grew in popularity, a process of social learning gradually took place. It is true that orders generated by program trading dominated the trading in multiple-expiration periods and that traders learned to be very cautious of periods in which multiple contracts expired, the dreaded witching hours. However, the effects of the social learning that program trading induced had wider effects. From the perspective of most market participants, such events weakened the connection, which had existed previously, between the 'external world' and market behaviour. This disassociation meant that the validity of data collection and analysis, according to which traders assessed the predicted market value of stocks were also put under threat. For example, a seasoned trader was quoted in early 1986 as saying: "Who needs analysis? Who cares about [companies] earnings, what the economy does, what the advance/ decline looks like? All you need is the basis," (Reier, 1986). The 'basis' is the common name for the spread between the index futures' price and the average price of the stocks. This situation also threatened the credibility of stock analysts, as an analyst admitted: "The trading programs are making very short-term technical analysis virtually impossible. It exacerbates any move in the markets and the following day the downswing is much more violent than it need be," (Reier, 1986). The weakening of traditional methods for the interpretation of markets' behaviour introduced a new phase of social learning. Market participants learned not to trust signs that previously had guided their trading. During 1986, the year in which program trading made its biggest growth, volatile, unpredicted market conditions - witching hours - were no longer confined to periods in which multiple expirations took place. We can understand the nature of this phenomenon better by focusing on one of the dramatic price drop events of the 1980s, which happened on the $11^{\text {th }}$ and the $12^{\text {th }}$ of September 1986. On $7^{\text {th }}$ of July that year, the Dow Jones Industrial Index made a record daily drop of 61.87 points and between that point and early September the market showed high volatility, but gradually climbed to a record level of 1919.71 on the $4^{\text {th }}$ of September (Securities and Exchange Commission, 1987).

The $11^{\text {th }}$ of September that year was a Thursday, and was not a date in which multiple expirations of the major futures contracts were to take place. Yet, selling of futures contracts in the Chicago Mercantile Exchange, where the S\&P 500 futures were traded, was followed by a modest drop in the New York Stock Exchange, in the first two hours of trading. This drop triggered several index arbitrage programs to issue sell orders. Normally, the large amounts of stock that such sales offered would motivate traders to buy the discounted stocks, and thereby to stop the selling. This indeed happened, but on a much smaller scale than was needed to meet the supply. In the following hours, some traders took advantage of this trend and started to buy the now-cheaper stocks. However, the sudden drop in prices was a cause for concern for many traders, especially among those who managed medium sized portfolios, who decided not to 'go against the tide' and did not buy (Anonymous, 1986). As the majority of traders generally decided against buying stocks on the $11^{\text {th }}$, the prices continued to spiral downwards. On that day, Stocks at the New York Stock Exchange lost $4.61 \%$ of their value. The following day witnessed a continuation of the same trend, albeit more modestly. On Friday, the $12^{\text {th }}$, most traders still did not buy the heavily discounted stocks in quantities that would help the market to 'bounce back' to its previous prices. As a result, trading programs 
initiated more sales that pushed the prices down even further. A similar scenario took place in derivatives markets, where the futures' side of the index arbitrage was traded: September S\&P 500 contracts, for example, lost more than $7 \%$ of their value during trading on the $11^{\text {th }}$ and the $12^{\text {th }}$ of September (Greising, 1986).

The events of September 1986 brought to the fore the realisation that the rules, according to which prices were predicted, were put under considerable strain. Under normal conditions, a price drop like the one that occurred on the morning of the 11th of September would have attracted many traders to buy the discounted stocks, hoping to make profits. According to a popular perspective, commonly known as 'fundamental analysis', prices of relatively stable stocks (like those of the S\&P 500) represented fundamental values that were determined outside the market and a change in the prices could only follow new information about the companies. Sudden, unexplained price drops in such stocks, were to be seen as temporary, followed by 'technical corrections' in which the prices would return to their previous levels and therefore represented opportunities to make profits.

However, the growing popularity of program trading in the previous several years eroded gradually the validity of this popular view. Since in September 1986 there existed no alternative 'paradigm' that could explain to the traders why prices behaved the way they did and offer guidance as to what steps could be taken, many traders preferred to stay out of the markets and not to buy the cheap stocks. As a result, the sale orders of the arbitrage programs, which were not met by parallel buys, continued to push prices downwards, resulting in a dramatic market drop. An indication to this paradigmatic confusion that took hold of financial markets can be found in the New York Times editorial column from the following Sunday, the $14^{\text {th }}$ of September. Summarising the demise of existing market knowledge: "The stock market has long proven to be one of the most reliable predictors of the economic future. But at times it behaves no more rationally than a panic-stricken mob," (1986).

There were other indications that a fundamental change took place in the view of the investing public. Stoll and Whaley (Stoll and Whaley, 1990) analysed the prices and trading volumes of stocks. The period they analysed was between June 1984 and December 1986, the period in which the popularity of index arbitrage programs grew immensely. Two groups of stocks were checked: stocks that belonged to the S\&P 500 index and ones that did not. Special attention was given to multiple expiration days - triple witching Fridays. Prices on those dates were compared with the prices of the same stocks on the following Monday, a normal trading day. The assumption behind this comparison was that if program trading had an effect on the prices on the concluding hours of trading on a Friday, then, given that there were no external events that create fundamental changes in the overall price level, this effect would be reversed on the following Monday. The results showed that the differences in 'price reversals' between stocks that belonged to the S\&P 500 (and were effected potentially from program trading $)$ and between ones that did not belong to the index were marginal $(0.24 \%$ and $0.006 \%)$.

This result, on its own, supported the argument that program trading did not contribute to market instability. However, a closer look at the results shows a worrying trend. The price reversals were expected to be symmetrical. After all, the 'technical' reason that caused prices to drop on the Fridays - heavy program trading - did not exist on the following Mondays. Nonetheless, price reversals tended not to be symmetric. Fridays on which there was active program trading, and on which stock prices dropped to a level that would allow potential profit (that is, drops were larger than transaction costs) were followed by a period of several days in which prices kept trailing at lower levels, instead of 'bouncing back' to their previous 
levels. As the events of September $11^{\text {th }}$ and $12^{\text {th }}$ show, this phenomenon may indicate that market participants were reluctant to buy on the Monday the stocks that dropped in price the previous Friday.

This shows how second-order dangers can be produced by the unforeseen consequences of risk management systems. Influential program trading, performing index arbitrage, weakened the validity of one of the fundamental axioms of the market - 'buy low, sell high' - for many of the market participants. As a result, arbitrage transactions became harder to complete, and stock markets tended to become less liquid, more volatile and more dangerous. It has to be stressed that, on its own, program trading did not create the second-order danger. However, the combination of the computer-based trading strategy and the social reaction to that strategy contributed to the fact that small-scale traders found it increasingly hard to create and maintain a valid picture of the markets. Combined with the high volumes that the programs created, which contributed dramatically to price volatility, this constellation of factors brought about a less calculable and thus more dangerous market environment.

Index arbitrage was based on the existence of a correlation between prices in stocks and the futures markets. The link between the prices in the stock market and the derivatives one is composed of the decision-making process of a large number of market participants. In turn, decisions in the trading floors are based on expectations that various agents hold about the behaviour of prices. Paradoxically, the emergence of large-scale computerised trading strategies triggered forces that put the correlation between stock prices and futures prices, on which the success of arbitrage transactions was dependent, under stress.

The implicit assumption behind the algorithms of the index arbitrage programs was that the market participants are rational agents whose utility maximisation provides market liquidity unfailingly. For example, if prices drop, it is expected that there would be enough market participants who would take advantage of the low prices and buy. However, those programs did not account for their own influence on the market. That is, a market in which there exists an agent whose buying power, ability to absorb sales, and (presumably) information is superior to those of all of the rest, and is very different from the one that the programs 'prepare for'. For example, in such a market it would be rational, as the events of September 1986 showed, to follow an implicit directive from the most powerful player in the market and to sell in reaction to other sales, rather than buy. This, then, leads to the creation of secondorder dangers: the higher the volume of trading that an index arbitrage programs manages, the more different the market in which it operates will be from the world described in its computer code, and, consequently, the greater the danger of market failure.

\section{Second Case Study: Long-Term Capital Management (LTCM)}

A more recent example of mathematical risk management leading to unforeseen second-order dangers is provided by the near-collapse of the hedge fund Long-Term Capital Management (LTCM), a highly successful and extremely professional hedge fund, in summer 1998. Compared with the preceding case, LTCM combines most of the elements of the emergence of second-order dangers in one particular organisation. Even more than the case of program trading, LTCM stands for the way in which mathematical finance has made an impact on and indeed transformed financial markets. In the late 1990s - and maybe still today - LTCM was the 'epitome of modern risk management' (de Goede, 2001: 151) - and still failed dramatically. 
LTCM was founded in 1993 by seasoned Wall Street bond trader John Meriwether and quickly gained a reputation for hiring the most experienced traders and specialists in quantitative finance; it also had two of the developers of the Black-Scholes options pricing formula among its executives. In contrast to the publicly held view of hedge funds as highly speculative enterprises, LTCM actually avoided any kind of risky speculation based on hunches and intuitions. Its portfolio was based on the application of carefully researched mathematical models and focused on established markets in industrial countries, particularly in government bonds.

LTCM's main trading strategy was to use arbitrage. Arbitrage exploits price differences between two similar assets in one market or the same asset in different markets. For instance, various factors may lead to a temporary discrepancy between, say, the prices of Royal Dutch shares in Amsterdam and Shell shares in London, although both concern the same business entity and thus should have the same profit expectations. Arbitrageurs will then buy the cheaper of the assets and 'short-sell' the more expensive ones, thus raising demand and supply, respectively. As a result, the discrepancy will disappear. The 'art' of arbitrage consists in identifying such discrepancies for exploitation (cf Beunza/ Stark) ${ }^{9}$.

For a couple of years, LTCM was highly successful and profitable and indeed widely regarded as 'the world's greatest money machine' (Dunbar, 2000: 179). That success story ended rather abruptly in 1998, when LTCM came into problems after the Russian default on debts denominated in roubles. Although LTCM itself had only minor exposure to the events in Russia, it suffered from the subsequent 'flight to quality' during which investors sought to sell precisely those high-risk, less liquid assets that constituted a major part of LTCM's portfolio (Dunbar, 2000; MacKenzie, 2000: 284). The resulting market movement against the fund and the increasingly nervous attitude of investors and counterparties made it impossible for LTCM to raise further capital and eventually brought it close to bankruptcy. Fearing the potential systemic consequences of a collapse, the Federal Reserve Bank orchestrated a rescue operation involving the major creditors and the gradual unwinding of the major part of LTCM's portfolio.

If the example of LTCM only demonstrated the failure of the toolkit of modern mathematical risk assessment, it would not as such be an illustration of the production of second-order dangers in financial markets. Yet, LTCM's story includes another aspect, an aspect that relates it to the development of second-order danger. As MacKenzie (2003) shows, on its own, the 'flight to quality' in the wake of the Russian crisis alone does not provide a full explanation for the extraordinary fate of LTCM. MacKenzie argues convincingly that LTCM's problems were exacerbated by a social process of 'imitation': a trading technique that was believed to be successful led to widespread imitation among market participants. Many other market participants believed that LTCM had superior prediction tools to the ones they used and therefore decided to track and replicate LTCM's positions and essentially to imitate the fund's trading strategy. This imitation led to the creation of what MacKenzie dubs a 'superportfolio'. The superportfolio was the aggregate of partially overlapping market positions held by the different market participants. Although the ownership of the vast array of assets composing the superportfolio was dispersed, 'seemingly unrelated instruments became linked by common ownership' (Gallati, 2003: 472). The fact that the portfolio managers followed similar trading heuristics resulted in relatively uniform behaviour. This behaviour accentuated and amplified existing market trends.

\footnotetext{
${ }^{9}$ That arbitrage is not always risk-free under real world conditions (for instance if 'irrational' investors persist) has been highlighted by the behavioural finance literature Shleifer, (2000) Similarly, LTCM's activities were not strictly speaking risk-free, and they also required capital.
} 
A feature of the market situation in 1998 that compounded the problem of herd behaviour and led to the unravelling of the superportfolio is especially pertinent to our argument: the widespread usage of value-at-risk-models as a management tool that resulted in a 'run on the bank'- phenomenon (MacKenzie, 2003: 33ff). Value-at-risk (VaR) is a widely used method to produce an overall measure of the exposure of a firm or its subdivisions to market risk (cf Crouhy, Galai et al. 2001). VaR measures use the portfolio approach of Markowitz (1959) to produce a concise statement of a firm's risk position. The randomness of price movements is represented by a stochastic model that estimates the likelihood of specific losses. VaR thus enables decision-makers to limit the exposure to a predefined threshold. Unlike portfolio insurance, the $\mathrm{VaR}$ approach is not a computerised instrument to program trading activities. Rather, it is a mathematical tool that informs decision-making and thus leaves room for discretion.

However, if used as a management tool, VaR can lead to replication, and some observers argue that this happened in 1998 (Dunbar, 2000: 176ff). If the results of a VaR-calculation are used to control the exposure of subdivisions or individual traders within a firm, risk officers may force them to liquidate positions to decrease the overall VaR level. Thus, traders may be forced to 'lock in' their losses despite their - possibly reasonable - belief that holding the position will eventually pay off. Since VaR levels rise in times of increased volatility such as in the summer of 1998, VaR-systems contribute to replication: within those asset classes with high volatility, many traders have to cut their positions, thereby only contributing to a general downward movement. Mechanistic risk managements based on VaR measures can override individual perceptions of risk and thus produce a surprisingly homogeneous population of replicated risk strategies. Similar to the downward spiral initiated by program trading in 1987, the reliance on VaR systems within trading organisations can thus result in an unexpected lack of liquidity in the market. Such a 'vicious circle' is not a necessary consequence of VaR systems; it can be avoided, for instance, by using price averages over a longer period and slowly updating risk levels (Jorion, 2002). The experience of LTCM's crisis supports that such 'buffering devices' may indeed be necessary to avoid a rapid deterioration of liquidity.

Yet in 1998, LTCM was faced with the problem that it could not find counterparts for many of its - entirely reasonable - deals anymore: 'dealers, who would [normally] be willing to buy or sell those positions were simply unwilling to do it' (Shaw cited in MacKenzie, 2003). The organisationally produced 'unwillingness' of the market to trade the assets most prominent in LTCM's portfolio in turn created a highly illiquid market situation that was unforeseeable under normal circumstances.

This example shows that LTCM's risk assessment system, arguably one of the most advanced in the financial world at the time, failed to assess the influence that its use had on other market participants. The growing imitation which led to the formation of the superportfolio are attributed to the popular belief among market participants that LTCM's risk assessment tools were better than theirs and therefore its moves should be followed. In the volatile market of summer 1998, however, the replication of both market positions and strategies led to the unravelling of that superportfolio: while many market participants were trying to get rid of the very same positions (and prices therefore deteriorated), there were fewer and fewer counterparties to undertake risk. In fact, as LTCM's Meriwether argued in a letter to investors, the increasing spreads of August 1998 actually offered great arbitrage opportunities. However, no one was willing to take them. The crisis thus did not only hit LTCM but the global arbitrage business that has not recovered since. The corresponding persistence of relatively high spreads (due to relatively low arbitrage activity) may well be seen as another second-order danger produced by the replication of risk strategies. 
Although the LTCM case ended in dramatic results, it did not even involve strong connectivities. The market participants whose moves created and maintained the superportfolio had no information on the actual methodology that was used in LTCM in order to produce its portfolio. All the other participants could see were the outcomes of the invisible methodology, namely, the transactions. It is likely that a more comprehensive knowledge of a risk assessment system - knowledge and understanding of the methodology used - would lead to even more unified, therefore potentially destructive, market behaviour. It should be noted that in the specific case of LTCM it was possible that the very fact that other market participants did not know the details of the decision-making process behind LTCM's transactions played an important role in the formation of the herd behaviour. That is, the limited information about the trading scheme combined with the near-legendary status of some of LTCM's people created a situation in which a detailed decision-making process was replaced by one based on the belief that 'others know better'. Yet it simultaneously laid the foundation for the fundamental mistrust of LTCM's positions at a later stage: since the reasons for LTCM's success as much as the reasons for its problems remained opaque at that time, even rational profit opportunities were eschewed. LTCM has become a victim of its own success.

The market conditions of summer 1998 resulted in extremely adverse market movements to LTCM's holdings. Yet it was not the adverse market situation alone that resulted in LTCM's near-collapse. By the sheer size of its investments, LTCM had already become a significant part of the markets it was seeking to analyse. That made it increasingly difficult to regard its trading strategy as a merely passive, chance-exploiting behaviour (de Goede, 2001: 160). More importantly, however, LTCM's highly successful investment strategy was replicated by other market participants. LTCM's risk strategies were perceived to be so successful that others replicated them. This changed the very assumption on which LTCM's portfolio was based, ie that LTCM's transactions would have market-wide implications. Contrary to these assumptions, which were embedded in the techno-social apparatus of the hedge fund (and in those of many other market participants), LTCM's trading decisions, amplified through replication by others, did have considerable effect on the bond market as a whole. As a result, LTCM was no longer able to make independent decisions about its portfolio (ie to make a risk-based decision). Instead, the hedge fund became subject to a multitude of decisions of others and to the dangers created by them. The unforeseen effects of replication turned the finely tuned risk management machine of LTCM into a rather crude instrument that did not take into account its own contribution to the very risks it was designed to cope with.

The case of LTCM illustrates the complex sources of second-order dangers: it would be wrong to conclude that LTCM's original risk strategies were false or irrational. As mentioned before, LTCM's risk strategies were so successful that others replicated them. Yet this changed the very assumption on which LTCM's portfolio was based, ie that it was possible to operate a 'gigantic vacuum cleaner sucking up nickels from all over the world' (Merton in an interview, cited by de Goede, 2001: 158). The image thus projected and actually enacted by LTCM's risk management was a rather passive one. It looked at opportunities and possible market movements from a detached, statistical perspective that could not adequately reflect the extent to which those were actually shaped by LTCM itself. Thus, perfectly rational and sophisticated methods of risk assessment could result in unforeseeable second-order dangers both for LTCM and for others. Due to the last-minute bailout, the fund did not collapse immediately (although it ceased trading in the year 2000). It is not entirely clear whether claims that LTCM's collapse would have indeed threatened the stability of the global financial system were exaggerated, in order to justify the bailout. It is obvious, however, that 
the LTCM crisis has implications for widely used methods of mathematical risk management that go beyond this specific case.

\section{Discussion}

The two case studies of second-order dangers in financial markets show a problem inherent in today's leading risk management methods: the economic models on which the systems are based are not 'reflexive'. That is, the models do not account for the influence they have on the markets as a whole. By employing financial theories to predict potential losses and market movements, they generally assume that 'when financial theories are turned into practice there is no change to the underlying reality' (Chancellor, 1999: 345). Yet, as the cases show, financial markets are environments in which the true impact of decisions cannot be described fully by the invariant laws of mathematical models. It hinges on the reaction of other market participants to the perceived impact of those decisions. Although a theory may be a good description of what happens in a world in which that theory is unknown, it is not always a good predictor for what happens once everyone uses it: "To the extent to which that theory is believed and acted upon, it becomes part of the world it describes," (MacKenzie, 2000: 281). Yet, the world that includes the theory as something that people act upon is different from the one without it. Paradoxically, the theory may thus lose its descriptive value once it becomes part of the phenomenon it describes. Risk assessment methods do not usually take that into account and may thus contribute to the creation of second-order dangers in the markets.

Second-order dangers in financial markets therefore turn out to be the paradoxical consequence of the increasing sophistication and quantification of the financial risk assessment. From the perspective of a single market participant, financial risk assessment has a great potential to transform the uncertainties of the market into manageable risks. However, as part of a larger network of technological and social relations those strategies turn out to be partially self-defeating. Since the source of second-order dangers is relational rather than individual, one should not expect more sophisticated methods of risk assessment to do away with such phenomena. This fact is troubling for both the market participants, who continually seek to minimise the risks of their decision, and for regulators, who must seek to minimise the unintended side effects of risk construction if it threatens to undermine market stability. Let us briefly address the consequences for those two sets of actors.

Second-order dangers are problematic for market participants because they cannot be attributed to factors outside the market (ie external dangers). Second-order dangers are the unintended but inevitable by-products of methods of risk construction that project an image of actors with stable preferences and of markets without mechanisms of positive feedback. To the extent that such assumptions represent a simplification of actual conditions their merit may be compared to the one of Newtonian mechanics in modern physics: under normal everyday conditions, they work fine, but near the speed of light, their predictive value is low. Yet, those situations of extreme volatility are exactly the situations where mathematical risk management is needed the most. Our examples do not lead to the conclusion that financial markets are in any way more prone to systemic failure than before. Rather, the appropriate interpretation could be regarded as a specific variant of the 'risk society' thesis (Beck, 1992; 1999). Financial markets are not necessarily more unstable or unpredictable than before, but their instabilities are increasingly related to processes internal to the markets and to the organisations operating within them - rather than to external events.

If second-order dangers are produced in and by financial markets, are they the consequences of particular complex socio-technical systems prone to 'normal accidents' (Perrow, 1984)? 
Normal accidents occur in systems that are often designed to deal with risk, eg petrochemical plants, airway controls or nuclear power plants. As a result of his study of Three Mile Island and other accidents, Perrow identified two characteristic traits of systems prone to normal accidents: tight coupling and interactive complexity. Not all complex systems are accidentprone, because most of them incorporate enough 'slack' and buffers to prevent critical failures from propagating. This is what Perrow calls 'loose coupling': processes in one part of the system are not immediately affected by those of other parts. However, some socio-technical systems such as nuclear power plants involve a 'tight coupling' of their constituent parts. Then, whatever 'happens in one directly effects what happens in the other' (p 90). Without designed-in safety devices, failures in tightly coupled systems spread from one part of the system to another and easily lead to severe accidents. Although financial markets are not tightly coupled systems per se, the parallel to the aforementioned prominence of technological and social connectivities is obvious: when decision-making is uniformly guided or even programmed by similar routines, behaviour in financial markets may indeed become 'tightly coupled'. The synchronisation of decision-making processes through uniform risk strategies can replace the loose coupling that would otherwise guarantee that decisions are made independently.

In financial markets, however, the problem of second-order danger goes beyond the normal accident model. There is not necessarily an 'error' that is propagated throughout the system. Rather, the replication of perfectly rational and successful risk strategies becomes a source of second-order danger. The point is not that individual risk strategies fail, but that they produce aggregate effects that undermine their own assumptions. In other words, mathematical risk assessment in financial markets is confronted with a problem of reflexivity: models of the market do not include the models in the market. They cannot account for the aggregate effects of synchronised decision-making precisely because they are based on the assumption that any individual transaction only has a negligible effect on price movements. While this is trivially true, it fails to take into account that the aggregation of individual but parallel transactions has such an effect.

Second-order dangers are beyond the currently dominant perspective on risk management. The strategies discussed in the examples do not, and indeed cannot, take into account how their assumptions are modified by the intrusion of those very models into social reality. Second-order danger cannot be attributed to anyone's decision in particular. Similarly, they are not divine interventions or physical events removed from decision-making. They are built into social structures and concern the way decisions are made and markets operate. One might claim that better software - that accounts for the effect of its own operations on the market could eliminate such dangers. Yet such a solution would mean to jettison one of the fundamental assumptions of financial economics, and indeed economics in general: the assumption of rational, individualistic agents. Rather than to re-establish the usefulness of mathematical risk management, that would shake the core of the influential socio-technical institution that is based on application of financial economics' theories - contemporary financial markets. Hence, eliminating the second-order danger would ultimately mean to change the fundamentals of financial markets, as we now know them.

If our analysis is correct and the application of models-based risk management may result in the creation of second-order dangers, then this raises questions about the recent move of financial regulators worldwide toward an integration of mathematical risk assessment tools into the regulatory framework ${ }^{10}$. We have shown how certain methods of dealing with

\footnotetext{
${ }^{10}$ One of the most notable manifestations of this trend is the current reform of international capital adequacy standards (Basel II). See Gallati, (2003).
} 
financial risk have failed to take into account their impact on the market environment. If regulation now aims to peruse those very methods to ensure overall market stability, it appears to gloss over the fundamental difference between the risk construction process and the second-order dangers thus created. The difficult if not paradoxical task for regulators is to design a framework that translates second-order dangers into the risk perceptions of market participants. Alas, there is not a straightforward translation between the two. It is thus difficult to conceive of a more sophisticated risk management technology that would be able to avoid current shortcomings (such as the lack of reflexivity). If financial regulation adopts an approach that uses the same tools for regulation that market participants use to control their risks, they are not likely to solve the problem of reflexivity. As indicated earlier, taking second-order dangers seriously implies a more distanced look at the benefits and problems of contemporary mechanisms of risk construction in financial markets.

The mathematical models used in this construction are useful devices to deal with the fundamental uncertainty about the future. They help to deal with but cannot eliminate ignorance. It would therefore be wrong to attribute to those models the ability to prevent losses and accidents from happening. As Merton wrote, 'the mathematics of the models are precise, but the models are not, being only approximations to the complex, real world.' (cited in de Goede, 2001: 159). For regulators in particular, it does not make sense to expect models to make increasingly 'accurate' predictions. Rather, regulators have to turn their attention to how mathematical models shape the very market environment they are supposed to mirror. It is debatable whether isolated 'stress tests' of models can substantially contribute to that task. Regulatory supervision with an eye on second-order dangers would have to focus on interaction effects that are evidently difficult to establish in a laboratory situation. Yet the alternative is to use society or financial markets as 'real world laboratories' (cf Krohn and Weyer, 1989), the results of which we have discussed above. There is no reason to believe that second-order dangers will be the reason for a major failure of the financial system in the near future. However, as the introduction of advanced risk technologies continues, the possibilities for such an event will certainly increase.

\section{References}

Anonymous (1986). Automated Selling Generates Biggest One-Day Decline As Volume Sets a Record. Wall Street Journal. New York.

Anonymous (1986). The Dow Plunges - Trying to Compute Madness of Crowds. New York Times. New York.

Baecker, D. (1997). Durch diesen schönen Fehler mit sich selbst bekannt gemacht: Das Experiment der Organisation. Riskante Strategien. Beiträge zur Soziologie des Rechts. T. Hijikata and A. Nassehi. Opladen, Westdeutscher Verlag: 249-271.

Baecker, D. (1999). Organisation als System. Frankfurt/ Main, Suhrkamp.

Beck, U. (1992). Risk Society: Towards a New Modernity. London, Sage.

Beck, U. (1999). World Risk Society. Cambridge, Polity.

Bernstein, P. (1993). Capital Ideas: The Improbable Origins of Modern Wall Street. New York, The Free Press. 
Black, F. and Scholes, M. (1973). The pricing of options and corporate liabilities. Journal of Political Economy 81 (637- 654).

Bonß, W. (1995). Vom Risiko: Unsicherheit und Ungewißheit in der Moderne. Hamburg, Bund.

Bryan, L. and Farrell, D. (1996). Market Unbound. Unleashing Global Capitalism. New York, Wiley \& Sons.

Caytas, I. G. (1992). Moderne Finanzinstrumente. Band 1: Theoretische und anwendungsorientierte Grundlagen. Stuttgart, Schäffer-Poeschel.

Chancellor, E. (1999). Devil Take the Hindmost. A History of Financial Speculation. New York, Farrar, Straus and Giroux.

Crouhy, M., Galai, D. et al. (2001). Risk Management. New York, McGraw-Hill.

de Goede, M. (2001). Discourses of scientific finance and the failure of Long-Term Capital Management. New Political Economy 6 (2): 149- 170.

Dunbar, N. (2000). Inventing Money. The Story of Long-Term Capital Management and the Legends Behind It. Chichester, Wiley \& Sons.

Esser, H. (1990). Habits, Frames und Rational Choice. Zeitschrift für Soziologie 19: 231- 247.

Gallati, R. (2003). Risk Management and Capital Adequacy. New York, McGraw-Hill.

Greising, D. (1986). Traders get taste of futures shock. Chicago Sun-Times. Chicago.

Harrison, J. R. and March, J. G. (1984). Decision making and post-decision surprises. Administrative Science Quarterly 29 (1): 26- 42.

Hull, J. C. (1997). Futures, Options and Other Derivatives. Upper Saddle River, NJ, Prentice Hall.

Jorion, P. (2002). Fallacies about the effects of market risk management systems. Financial Stability Review December: 115- 127.

Knight, F. H. (1921). Risk, Uncertainty and Profit. Boston, Houghton Mifflin.

Krohn, W. and Weyer, J. (1989). Die Gesellschaft als Labor. Die Erzeugung sozialer Risiken durch experimentelle Forschung. Soziale Welt 40: 349- 373.

Lowry, R. P. (1984). Structural changes in the market. The Social Dynamics of Financial Markets. P. A. Adler and P. Adler. Greenwich, CT, JAI Press: 19- 40.

Luhmann, N. (1990). Risiko und Gefahr. Soziologische Aufklärung 5. Opladen, Westdeutscher Verlag: 131- 169. 
Luhmann, N. (1990). Technology, environment and social risk: a systems perspective. Industrial Crisis Quarterly 4: 223- 231.

Luhmann, N. (1991). Soziologie des Risikos. Berlin/New York, Walter de Gruyter.

Luhmann, N. (2000). Organisation und Entscheidung. Opladen, Westdeutscher Verlag.

MacKenzie, D. (2000). Long-Term Capital Management: A sociological essay. Facts and Figures: Economic Representation and Practices (Jahrbuch Ökonomie und Gesellschaft 16). H. Kalthoff, R. Rottenburg and H.-J. Wagener. Marburg, Metropolis: 277-287.

MacKenzie, D. (2003). An equation and its worlds: bricolage, exemplars, disunity and performativity in financial economics. Social Studies of Science forthcoming.

MacKenzie, D. (2004). The Big, Bad Wolf and the Rational Market: Portfolio Insurance, the 1987 Crash and the Performativity of Economics. Economy and Society forthcoming.

MacKenzie, D. (2004). Social connectivities in global financial markets. Environment and Planning D: Society and Space 22 (1): 83- 101.

Mackenzie, D. and Millo, Y. (2003). Negotiating a Market, Performing Theory: The Historical Sociology of a Financial Derivatives Exchange. American Journal of Sociology 109 (1): 107-145.

Markowitz, H. M. (1959). Portfolio Selection - Efficient Diversification of Investments. New York, John Wiley \& Sons.

Merton, R. C. (1973). Theory of rational option pricing. Bell Journal of Economics and Management Science 4: 141- 144.

Perrow, C. (1984). Normal Accidents: Living with High-Risk Technologies. New York, Basic Books.

Reier, S. (1986). Program Trading Nightmare for technical analysts. Investment Management World.

Schwartz, E. W., Hill, J. M. et al. (1986). Financial Futures. New York, Dow Jones-Irwin.

Securities and Exchange Commission, S. (1987). The Role of Index-related Trading In The Market Decline on September 11 and 12, 1986

A Report by the Division of Market Regulation, SEC. Washington, D.C., Securities and Exchange Commission: 1- 28.

Shackle, G. L. S. (1979). Imagination and the Nature of Choice. Edinburgh, Edinburgh University Press.

Shleifer, A. (2000). Inefficient Markets. Oxford, Oxford University Press. 
Short, J. F., Jr. and Clarke, L.Eds. (1992). Organizations, Uncertainties, and Risk. Boulder, CO, Westview Press.

Steinherr, A. (1998). Derivatives: The Wild Beast of Finance. New York, Wiley \& Sons.

Sterngold, J. (1986). 'Triple Witching Hour' Havoc, Scene Scare Professionals. New York Times. New York.

Stoll, H. R. and Whaley, R. E. (1990). Program Trading and Individual Stock Returns: Ingredients of the Triple-Witching Brew. Journal of Business 63 (1), Part 2: A Conference in Honor of Merton H. Miller's Contributions to Finance and Economics): S165-S192. 